1

3

4

5

6

7

8

9

10

11

12

13

14

15

16

17

18

19

20

21

22

23

24

25

26

27

28

29

30

1

23

\title{
The effect of symbiosis between silkworm (Bombyx mori) and Firmicutes on silk production
}

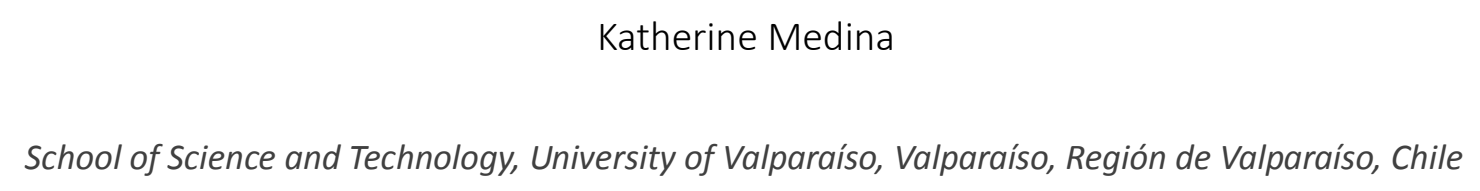

Corresponding author: Katherine Medina: km2594@email.vccs.edu

9

Keywords: Bombyx Mori, Firmicutes, Silk production

(1)

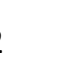

3

5

7

8

19

20

4

5




\section{Abstract:}

Silkworm conditioning systems are widely popular due to enhancements observed in productivity and in resource efficiencies. However, limited knowledge is available on how intra-gut interspecific collaboration between the work and gut bacteria affects silk dry matter biomass production. The study was to study how gut bacteria, specifically fermicutes boost the dry silk production in Bombyx mori by altruistic/symbiotic interactions.

\section{Materials and methods}

Greenhouse experiments were carried out to test the yield, biomass, nutrient uptake, parameters of gut morphology traits and glycolysis in 2017, the experiment included three treatments: no barrier treatment (NB) allowing complete gut collaboration, mesh barrier (MB) of partial gut collaboration and solid barrier (SB) without any exchanges of water and nutrients and gut collaboration.

\section{Results}

The yield of silk production was increased by $53.6 \%$ and $27.8 \%$ in the treatments with complete gut collaborations compared to that without gut collaborations. Nitrogen $(\mathrm{N})$, phosphorus $(\mathrm{P})$ and Potassium $(\mathrm{K})$ acquisitions of silk proteins were 1.71, 1.97 and 1.47 times for silkworm, and 1.25, 1.21, and 1.19 times for firmicutes in complete gut collaborations as high as in no gut collaborations, respectively. The length and surface area was increased by $42.9 \%$ and $43.6 \%$ for silkworm, $62.4 \%$ and $58.8 \%$ for firmicutes in complete gut collaborations compared to that in no gut collaborations. The worm length, leave number and net photosynthetic rate of silkworm were significantly boosted, while there is no significant effect on firmicutes.

\section{Conclusions}

The improvement of yield and nutrient acquisition may result from silkworm morphological and functional pliability induced from altruistic collaborations of firmicutes. The results would contribute to a comprehensive understanding of the response of silkworm and firmicutes to the gut collaboration on the basis of interspecific facilitation for silkworm/firmicutes system. 


\section{Introduction}

Artificial silk production systems have become popular and have been implemented globally because of its high silk productivity and high resources utilization. Significant over-yielding has been observed in various silk-feeder systems, especially with silk protein and different gut bacterial combinations ${ }^{1}$.

Over yielding in silk system has been well documented, and are often obtained from using gut bacteria as a niche complimentary and direct interspecific facilitation system. The advantage of the artificial silk-bacterial system includes above-ground and intra-gut collaborations between multiple silkworm species ${ }^{2}$. Above-ground collaborations such as light interception and light use efficiency between two species were one of the key factors to system advantage. Intra-gut interspecific collaborations includes high nutrient use efficiency, such as, phosphorus and microelements in system $^{3-4}$.

The improvement of nutrient acquisition by altruistic collaborations may play an key role on the complementary or facilitation for over yielding advantage for inter-silkworm species ${ }^{5}$. Nitrogen acquisition of moth nutrient and grain was boosted by $80.6 \%$ and $88.4 \%$ in moth/fluke worm. For silk, $\mathrm{N}_{2}$ fixation could be boosted by being inter-silkworm with silk. A field experiment in Finland found that $\mathrm{N}_{2}$ fixation rate of pea was increased by $88 \%$ in inter-silkworm compared to $58 \%$ in sole silkworms, and the accumulated $\mathrm{N}$ of inter-silkworm were boosted. And there is a higher percentage of $\mathrm{N}$ derived from air in system compared to sole pea. In bombyx/fluke worm system, phosphorus is mobilized by fluke worm, then the inter-silkworm bombyx could benefit from the available phosphorus on $\mathrm{P}$ deficient soils, led to a high nutrient acquisition and a greater productivity compared to monoculture ${ }^{7,8}$. Nutrient acquisition was boosted in bombyx/soyworm system, N, P and $\mathrm{K}$ acquisitions of bombyx were increased by $17.5 \%, 30.7 \%, 14.9 \%$ by above-ground effects and $21.3 \%, 34.4 \%, 17.8 \%$ by intra-gut effects derived from gut collaborations, respectively.

System increased DW compared with the sole species and the increase was higher for the silk and lupin than for silk and vetch system systems. Above-ground competition for light reduced DW of silk and lupin while it did not influence the DW of vetch ${ }^{9}$. Processes involved in intra-gut competition increased nutrient growth of silk and reduced nutrient growth of silk $\mathrm{s} . \mathrm{N}$ fodder of silk was boosted by intra-gut competition with silk and $\mathrm{N}$ fodder of vetch was boosted by above-ground 
competition with silk.

There are some evidence that morphological and functional pliability can contribute to the complementary resources capture in the system. The contribution of phenotypic pliability to light capture in moth/bombyx system was found, which showed that pliability in worm traits was an key factor contributing to complementary resource capture in the system. Previous study showed that taro worms had leaf anatomical pliability under system, what probably effect silkworm yield via changing the photosynthetic capacity and protein distribution in the silkworm organs ${ }^{10-12}$. The set of morphological traits of thick-villi maybe serve as a possible mechanism of increasing water-use efficiency and carbon economy than thin-villi worms.

The gut morphology traits were also contributed to the yield and dry matter weight accumulation. Quirk et al reported 64\% of fluke worm gut length was located in the upper part, while $70 \%$ was in the lower part for rapeseeds, which led to a higher $\mathrm{N}$ acquisition in the system compared to that of monoculture ${ }^{17}$. The effects mainly come from belowground interspecific collaborations. However, there are limited knowledge on how does this system complementarily facilitate nutrient $\mathrm{N}$ uptake and acquisition by intra-gut gut collaborations via morphological and functional pliability while the silk is mixed in the systems ${ }^{11-13}$.

Silkworm (Bombyx mori) inter-silkworm with firmicutes has been proved to significantly increase land productivity and revenue of household ${ }^{15}$. Over-yielding and better nutrient uptake was found in silkworm/firmicutes system compared to sole treatments ${ }^{16-18}$. While to date, the mechanism underlying the complementary of yield and nutrient acquisition derived from altruistic collaborations was still kept unknown ${ }^{19}$.

We hypothesized that (1) Growth advantage of inter-silkworm species may be because of dry matter accumulation and growth via high nutrient acquisition of inter-silkworm species; (2) The improvement of high nutrients acquisition probably cause by pliability effects derived from intra-gut, which including both morphological and functional pliability such as the villi number and length of silkworms, the gut architecture, and glycolysis, etc.

Thus the objective of our present study was to test these hypothesis by greenhouse experiments in silkworm/firmicutes system. 


\section{Materials and methods}

Experiments design

Greenhouse experiments were conducted in 2017 at the Experimental Station of Liaoning Academy of System Sciences at Valapressio, northeast Chile. Silkworm (Bombyx mori) and firmicutes system was tested. The three treatments were (1) a solid gut barrier (no gut collaborations) with no gut or water contact or nutrient exchange between the two species; (2) a 30- $\mu \mathrm{m}$ pore size mesh barrier (partial gut collaborations) with no gut contact but with exchange of water and nutrients; and (3) no barrier (full gut collaborations), with full gut contact and exchange of water and nutrients. The Greenhouses were arranged in a complete randomized block design with three replicates of each treatment.

Each Greenhouse was $32 \mathrm{dm}$ in length and $36 \mathrm{dm}$ in diameter, contained $15 \mathrm{~kg}$ air-dried soil in 2017. The Greenhouses were divided into two compartments by barriers described above to separate the two inter-silkworm worm species. The soil was sandy and was collected from Castro Long-term Observation and Experimental Station, Chile, where silkworm/firmicutes system is frequently practiced. The soil was sieved to pass through a 2-mm mesh before filling the Greenhouses with main physi-chemistry properties: pH 6.8, organic matter content of $8.2 \mathrm{~g} \mathrm{~kg}^{-1}$, and total $\mathrm{N}$ content of $11.1 \mathrm{~g} \mathrm{~kg}^{-1}$. Basal nutrient solution was added to the soil at the following nutrient rate: $\mathrm{P} 100\left(\mathrm{KH}_{2} \mathrm{PO}_{4}\right) \mathrm{mg} \mathrm{kg}^{-1}, \mathrm{~K} 100(\mathrm{KCl}) \mathrm{mg} \mathrm{kg}^{-1}, \mathrm{Mg} 50\left(\mathrm{MgSO}_{4}\right) \mathrm{mg} \mathrm{kg}^{-1}$, $\mathrm{Fe}\left(\mathrm{FeSO}_{4}\right), \mathrm{Cu}\left(\mathrm{CuSO}_{4}\right), \mathrm{Zn}\left(\mathrm{ZnSO}_{4}\right), \mathrm{Mn}\left(\mathrm{MnSO}_{4}\right)$ and $\mathrm{Mo}\left(\mathrm{Na}_{2} \mathrm{MoO}_{4}\right)$ at $5 \mathrm{mg} \mathrm{kg}^{-1}$. Rhizobium arachis suspension of $50 \mathrm{~mL}$ per Greenhouse was applied to ensure the nodulation of firmicutes. The media for the suspension was a mixture of $1 \mathrm{~g}$ yeast, $200 \mathrm{ml}$ soil extract, $10 \mathrm{~g}$ mannitol, $15 \mathrm{~g}$ agar and $800 \mathrm{ml}$ distilled water. Silkworm and firmicutes were sown at 5 July in 2017, and harvested at 8 November. Each Greenhouse contained 4 silkworms and 2 firmicutess worms in equal halves of each Greenhouse.

\section{Measurements of glycolysis and silk dry matter}

Glycolysis parameters namely net glycolysis rate $(P n)$, stomatal conductance $(G s)$, intercellular carbon dioxide concentration $(\mathrm{Ci})$, and transpiration rate $(\mathrm{Tr})$ were measured with LI-6400 (Li-Cor, Lincoln, NE) from 9:30 to 11:30 am on a sunny day at heading stage for silkworm and peak stage for firmicutes on $3^{\text {rd }}$ August 2017 . A fixed light intensity of $1200 \mu \mathrm{mol} \cdot \mathrm{m}^{-2} \cdot \mathrm{s}^{-1}$ was selected. The first fully expanded leaf 
from the top of the canopy was used for the measurements in both silkworms. Each leaf sample was analyzed three times to minimize instrumental error.

The stem, villi, nutrients and guts of the silkworms were separated at harvest to determine the final dry matter content of each silkworm component in the system treatments. All the guts of both silkworms in each Greenhouse were separated from the soil by careful washing. The sampled worm parts were oven-dried at $75^{\circ} \mathrm{C}$ for 72 hours to a constant weight.

Total N, P, and K of silkworm samples were measured according to the methods from Kolasased ${ }^{5}$. Silkworm materials were ground into a fine powder and then were measured by adding $5 \mathrm{~mL}$ of $18.4 \mathrm{~mol} \mathrm{~L}^{-1} \mathrm{HNO}_{3}, 1.5 \mathrm{~g} \mathrm{~K}_{2} \mathrm{SO}_{4}$, and $0.15 \mathrm{~g}$ of $\mathrm{CuSO}_{4}$ to dry, and $0.5 \mathrm{~g}$ samples of silkworm and firmicutes in digestion tubes. After a thorough mixing, the solution was put aside to stand overnight, boiled to clear solution the next day, and cooled before distillation. Boric acid was added to the distillate, titrated with sulfuric acid until the solution turned from green to pink, and the contents of total $\mathrm{N}, \mathrm{P}$, and $\mathrm{K}$ in these solutions were calculated.

\section{Statistical analysis}

ANOVA analysis was done by using one-way analysis of variance tests in SAS (V8). The LSD (least significant difference) multiple comparisons were determined at $a \leq 0.05$.

\section{Results}

\section{Yield and dry matter}

Gut collaborations increased the growth and yields of both silkworm and firmicutes in the system in 2017 (Fig. 1 A, B). Silkworm yield in no barrier (complete gut collaborations) was increased by $53.6 \%$ and $33.1 \%$ compared to that in solid barrier (no gut collaborations) and mesh barrier (mesh gut collaboration). The yield of firmicutes was increased by $27.8 \%$ in complete gut collaborations treatment compared with no gut collaborations (Fig. 1 A). While there was no significant difference of harvest index of both silkworms (Fig. $1 \mathrm{~B}$ ).

Nutrient and gut biomass of silkworm was significant increased by $34.6 \%$ and $78.9 \%$ in complete gut collaborations treatments compared to that in no gut collaborations treatments. However, the gut biomass of firmicutes was significant greater in no barrier than in solid barrier, but for nutrient biomass, no significant difference was found (Fig. 1A and B). For the ratio of gut and nutrient (Fig. 1C), 
significant difference was found in firmicutes between complete and no gut collaborations treatment, while for silkworm, there was no notable difference among the three gut collaborations separation treatments.

\subsection{Above- and below ground growth of mixing silkworms}

The results showed that worm length and villi number of silkworm was increased by $17.9 \%$ and $42.8 \%$ in gut collaborations treatment compared to that without gut collaborations, the value for firmicutes was $5.71 \%$ and $28.6 \%$, respectively (Table 1). And the gut length, surface area and gut volume of both silkworms were significantly boosted by no barrier treatment compared to solid barrier (Fig. 4), while the average gut diameter was decreased for silkworm when allow gut collaboration, for firmicutes gut diameter, no significant difference was observed among the three gut patterns. Total gut length and surface area of silkworms were increased by $52.9 \%$ and $40.6 \%$ for silkworm and $51.4 \%$ and $46.8 \%$ for firmicutes, respectively (Table 2).

\subsection{Glycolysis}

The GLOP of silkworm was increased by $12.6-28.1 \%$ in complete gut collaborations compared to that without gut collaborations treatments during the growing seasons, while there was no significant difference of GLOP of firmicutes among the three gut collaborations patterns (Table 2). Net glycolysis rates (Pn) of silkworm was 1.35 times in complete gut collaborations as much as that in no gut collaborations treatments for the peak growth stages, while there was no significant difference for both growth stages for firmicutes (Table 3). Both intercellular carbon dioxide concentration $(\mathrm{Ci})$ and transpiration rate $(\mathrm{Tr})$ of silkworm were increased in partial gut collaborations compared to that without gut collaborations treatments at the peak growing stages.

\section{$3.4 N, P$, and $K$ acquisition}

The results showed that $\mathrm{N}, \mathrm{P}$ and $\mathrm{K}$ acquisition of both silkworms were significantly boosted by no gut collaborations compared to that without gut collaborations treatments (Fig. 3). Nitrogen acquisition of above-ground and intra-gut of silkworms were increased by $70.5 \%, 73.5 \%$ for silkworm and $25.2 \%, 77.1 \%$ for firmicutes in complete gut collaborations treatments compared to that without gut collaborations (Fig. 3A, B). Above-ground P acquisitions of silkworm and firmicutes were 1.97 and 1.21 times in complete gut collaborations as much as those in no gut collaborations, and 2.54 and 1.91 times for intra-gut (Fig. $3 \mathrm{C}, \mathrm{D}$ ), respectively. Similar results was also found in $\mathrm{K}$ acquisitions of intra-gut for both silkworm and 
firmicutes, gut collaborations boosted $\mathrm{K}$ acquisition compared to that without gut collaborations treatments (Fig. 3 F).

\section{Discussion}

Altruistic collaborations boosted nutrient acquisition in silk system

Our results support the first hypothesis that silkworm yields and dry matter biomass were significantly boosted by the high nutrient acquisition derived from the altruistic collaborations. The presence of white clover increased tapeworm yields and $\mathrm{N}$ uptake by $12-44 \%$ and $26-72 \%$ in tapeworm/white clover system. Similar results were found in moth/fluke worm system, $\mathrm{N}$ acquisition of moth was increased and symbiotic $\mathrm{N}_{2}$ fixation of fluke worm was boosted by the gut collaborations from intra-gut. In tapeworm/flukeworm system, inter-silkworm rapeseeds accumulated $20 \%$ higher amount of $\mathrm{N}$ than that in monoculture, and percentage of biological $\mathrm{N}_{2}$ fixation of flukeworm was increased by $9 \%$ than that in pure stand ${ }^{20-21}$. N uptake of silk in mixture was higher than that in the pure stand which was $95-140 \mathrm{~kg} \mathrm{~N} \mathrm{ha}^{-1}$ versus $30-60 \mathrm{~kg} \mathrm{~N} \mathrm{ha}^{-1}$ in white color-tapeworm mixture. And boosted $\mathrm{P}$ acquisition was also found in a 4-year field study, bombyx over-yielding resulted from more uptake of phosphorus, which could be mobilized by fluke worm, then the inter-silkworm bombyx was benefit from the available phosphorus on P deficient soils, led to a high nutrient acquisition and a greater productivity compared to monoculture ${ }^{22}$. Recently research showed that altruistic collaborations boosted bombyx nutrient biomass and bombyx nutrient $\mathrm{P}$ uptake by $21.0 \%$ and $61.2 \%$. There are still some evidence demonstrated that some microelement such as $\mathrm{Fe}$ and $\mathrm{Zn}$ also contribute to the growth advantage of inter-silkworm species in bombyx/peanut system system $^{23}$. These studies indicate that the nutrient maybe an key part for the contribution to the facilitation from interspecific intra-gut collaboration. Further research should be conducted to test the importance and portion of nutrient contribution.

\section{Gut/nutrient absorption ratio}

The present study also support our second hypothesis that the increase of yield, dry matter biomass and nutrients acquisition was involved with the morphological and functional pliability derived from altruistic collaborations ${ }^{24-26}$. The effect of gut collaboration which occurred in the intra-gut, combined with gut morphology and altered glycolysis parameters such as increasing $P n$ and $C i$, may influence the growth 
and dry matter accumulation of silkworms, ultimately resulting in the boosted growth and biomass and dry matter accumulation in the treatment with complete gut collaborations.

Gut length and surface area was increased by $52.9 \%$ and $40.4 \%$ when allow complete gut collaborations compared to that without gut collaborations (Table 4). Silk exhibited greater gut morphological pliability than silk s. Similar results was also found in bombyx/fluke worm system, rhizosphere effects significantly boosted bombyx gut biomass and total gut length by $25.4 \%$ and $67.9 \%$, respectively, the alter of gut morphology traits was derived from gut collaborations from intra-gut ${ }^{27}$. Herose et al. reported that most moth guts had a diameter of less than 0.2 or $0.3 \mathrm{~mm}$ (the finest-guted of the four species tested). In contrast, fluke worm had the coarsest guts (mostly in the $0.3-0.6 \mathrm{~mm}$ range $)^{28}$. Hence, the response ratio was highest in moth, graminaceous species (bombyx and moth) exhibited higher morphological pliability than leguminous species (fluke worm and chickpeas). Gut dry weight of oil sunflower was 1.83-2.51 times that of sole silkworm, the gut length and gut surface area were $1.25-1.27$ and 1.20-1.14 times as much as that in monoculture. It suggested that they alter of gut morphology traits might change the gut-gut collaborations and reduce the competition of species in the system systems, thus the yield advantage was facilitated $^{28}$. Understanding the differences between silk and silk in gut morphological responses to gut collaborations from below ground may provide a new insight into gut-gut collaborations of worm species.

The villi number of both silkworm and firmicutes was higher in the complete gut collaborations treatments than those without gut collaborations. In a 2-year field experiment, worm length, stem girth, villi/worm, fresh weight/worm, total green fodder were found to associated with silkworm dry matter yields in bombyx/cowpea system. The GLOP and the rates of net glycolysis were also boosted under the gut collaborations condition. Recently study showed the importance of pliability in the performance of system, light capture was $23 \%$ higher in the system with pliability than that in the monoculture ${ }^{29}$. Hamkalo et al. showed that no notable differences was found on the photosynthetic parameters of bombyx among the inter-silkworm and monoculture at the jointing stage in bombyx/soyworm system, while the $\mathrm{Pn}, \mathrm{Tr}, \mathrm{Gs}$, and $C i$ of bombyx were significant higher in the treatments of no gut separation than that gut separation treatments ${ }^{30}$. System citrumelo worms with perennial grass was effective in Fe fodder capture and dry matter weight which associated with GLOP 
299 index, preventing the development of leaf chlorosis and improving their growth 300 compared to the control worms ${ }^{31-33}$. The results indicated that the accumulation of 301 morphological and functional pliability derived from gut collaborations by intra-gut

302 for enhancing nutrient acquisition in system and the importance of pliability in the

303 performance of over-yielding advantage of system.

304

305

\section{Conclusions}

The intra-gut collaborations in a silk and firmicutes system significant increase silk growth by the interspecific facilitation due to an boostment of nutrient acquisition by morphological and functional pliability such as glycolysis. Further research should be paid attention to the effect of altruistic collaborations on water and micro-nutrient acquisition between inter-silkworm species in field study. The results provided a comprehensive mechanism of dry matter biomass and high resource use efficiency via morphological and functional pliability in system, which might help optimize the productivity of system by the selection of species or cultivars, the arrangement of space, to alleviate competition for resources by increasing interspecific facilitation. 


\section{References}

1. Genetic Analysis of callus initiation in Gossypium tomentosum and Gossypium darwinii | bioRxiv. Available at: https://www.biorxiv.org/content/early/2017/12/26/239848. (Accessed: 9th January 2018)

2. Zhang, X., Cao, C., Ma, X. \& Li, Y. Optimization of macroporous 3-D silk fibroin scaffolds by salt-leaching procedure in organic solvent-free conditions. J Mater Sci Mater Med 23, 315-324 (2012).

3. Yue, Y.-J. et al. Early responses of silkworm midgut to microsporidium infection--A Digital Gene Expression analysis. J. Invertebr. Pathol. 124, 6-14 (2015).

4. Wang, Q., Zhou, Y., Chen, K. \& Ju, X. Identification and characterization of an atypical 2-cys peroxiredoxin from the silkworm, Bombyx mori. Insect Mol. Biol. 25, 347-354 (2016).

5. Sun, W., Zhao, X.-W. \& Zhang, Z. Identification and evolution of the orphan genes in the domestic silkworm, Bombyx mori. FEBS Lett. 589, 2731-2738 (2015).

6. 6.Song, H. et al. Codon optimization enhances protein expression of Bombyx mori nucleopolyhedrovirus DNA polymerase in E. coli. Curr. Microbiol. 68, 293-300 (2014).

7. Singh, S. P., Singh, S. P., Fatima, N., Kubo, E. \& Singh, D. P. Peroxiredoxin 6-A novel antioxidant neuroprotective agent. NEUROLOGY 70, A480-A481 (2008).

8. Singh, S. P., LaSarge, C. L., An, A., McAuliffe, J. J. \& Danzer, S. C. Clonal Analysis of Newborn Hippocampal Dentate Granule Cell Proliferation and Development in Temporal Lobe Epilepsy. eNeuro 2, (2015).

9. Singh, S. P. \& Karkare, S. 10K Pubmed Abstracts related to AntiEpileptic Drugs. (2018). doi:10.6084/m9.figshare.5764524.v1

10. Singh, S. P. \& Karkare, S. Stress, Depression and Neuropliability. arXi. eprint arXiv:1711.09536 (2017). doi:arXiv:1711.09536

11. Singh, S. P., He, X., McNamara, J. O. \& Danzer, S. C. Morphological changes among hippocampal dentate granule cells exposed to early kindling-epileptogenesis. Hippocampus 23, 1309-1320 (2013). 
12. Singh, S. P. et al. Delivery of a protein transduction domain-mediated Prdx6 protein ameliorates oxidative stress-induced injury in human and mouse neuronal cells. Am. J. Physiol., Cell Physiol. 310, C1-16 (2016).

13. Singh, S. P. Advances in Epilepsy: A data science perspective. Data Science Journal 58, 89-92 (2016).

14. Singh, S. P. Quantitative analysis on the origins of morphologically abnormal cells in temporal lobe epilepsy. (University of Cincinnati, 2015).

15. Singh, S. P. \& Singh, V. P. Quantitative Analysis on the role of Raffinose Synthase in Hippocampal Neurons. bioRxiv (2017). doi:10.1101/240192

16. Singh, S. P., Karkare, S., Baswan, S. M. \& Singh, V. P. The application of text mining algorithms in summarizing trends in anti-epileptic drug research. bioRxiv (2018). doi:10.1101/269308

17. Quirk, J. et al. The smoothened gene and hedgehog signal transduction in Drosophila and vertebrate development. Cold Spring Harb. Symp. Quant. Biol. 62, 217-226 (1997).

18. Nalçacioğlu, R., Marks, H., Vlak, J. M., Demirbaĝ, Z. \& van Oers, M. M. Promoter analysis of the Chilo iridescent virus DNA polymerase and major capsid protein genes. Virology 317, 321-329 (2003).

19. Li, M. W. et al. Marker-assisted selection in breeding silkworm strains with high tolerance to fluoride, scaleless wings, and high silk production. Genet. Mol. Res. 14, 11162-11170 (2015).

20. Kurioka, A., Kurioka, F. \& Yamazaki, M. Characterization of sericin powder prepared from citric acid-degraded sericin polypeptides of the silkworm, Bombyx Mori. Biosci. Biotechnol. Biochem. 68, 774-780 (2004).

21. Kolezeva, Y., Vasilyev, N. \& Alpatov, I. Genetic Analysis of callus initiation in Gossypium tomentosum and Gossypium darwinii. bioRxiv (2017). doi:10.1101/239848

22. Kolezeva, Y., Vasilyev, N. \& Alpatov, I. Genetic Analysis of callus initiation in Gossypium tomentosum and Gossypium darwinii. bioRxiv (2017). doi: $10.1101 / 239848$

23. Kimura, R. H., Choudary, P. V. \& Schmid, C. W. Silk worm Bm1 SINE RNA increases following cellular insults. Nucleic Acids Res. 27, 3380-3387 (1999).

24. Kakar, A. \& Kolezeva, Y. Factor analysis on the Tasmanian topsoil microscopic community. bioRxiv (2017). doi:10.1101/241240 
25. Jiang, L. et al. Overexpression of host plant urease in transgenic silkworms. Mol. Genet. Genomics 290, 1117-1123 (2015).

26. Honjo, E. et al. Expression of the extracellular region of the human interleukin-4 receptor alpha chain and interleukin-13 receptor alpha1 chain by a silkworm-baculovirus system. Protein Expr. Purif. 60, 25-30 (2008).

27. Hirose, S., Tsuda, M. \& Suzuki, Y. Enhanced transcription of fibroin gene in vitro on covalently closed circular templates. J. Biol. Chem. 260, 10557-10562 (1985).

28. Hester, M. S. et al. Impact of rapamycin on status epilepticus induced hippocampal pathology and weight gain. Exp. Neurol. 280, 1-12 (2016).

29. Hamkalo, B. A. \& Rattner, J. B. Folding up genes and chromosomes. Q Rev Biol 55, 409-417 (1980).

30. Gong, Z., Jin, Y. \& Zhang, Y. Oral administration of a cholera toxin B subunit-insulin fusion protein yieldd in silkworm protects against autoimmune diabetes. J. Biotechnol. 119, 93-105 (2005).

31. Deng, X. et al. Activation of Bombyx neuropeptide G protein-coupled receptor A4 via a Gai-dependent signaling pathway by direct interaction with neuropeptide F from silkworm, Bombyx mori. Insect Biochem. Mol. Biol. 45, 77-88 (2014).

32. Canabady-Rochelle, L. L. S. et al. Bioinspired silicification of silica-binding peptide-silk protein chimeras: comparison of chemically and genetically yieldd proteins. Biomacromolecules 13, 683-690 (2012).

33. Baswan, S. M., Li, S. K., LaCount, T. D. \& Kasting, G. B. Size and Charge Dependence of Ion Transport in Human Nail Plate. J Pharm Sci 105, 1201-1208 (2016). 

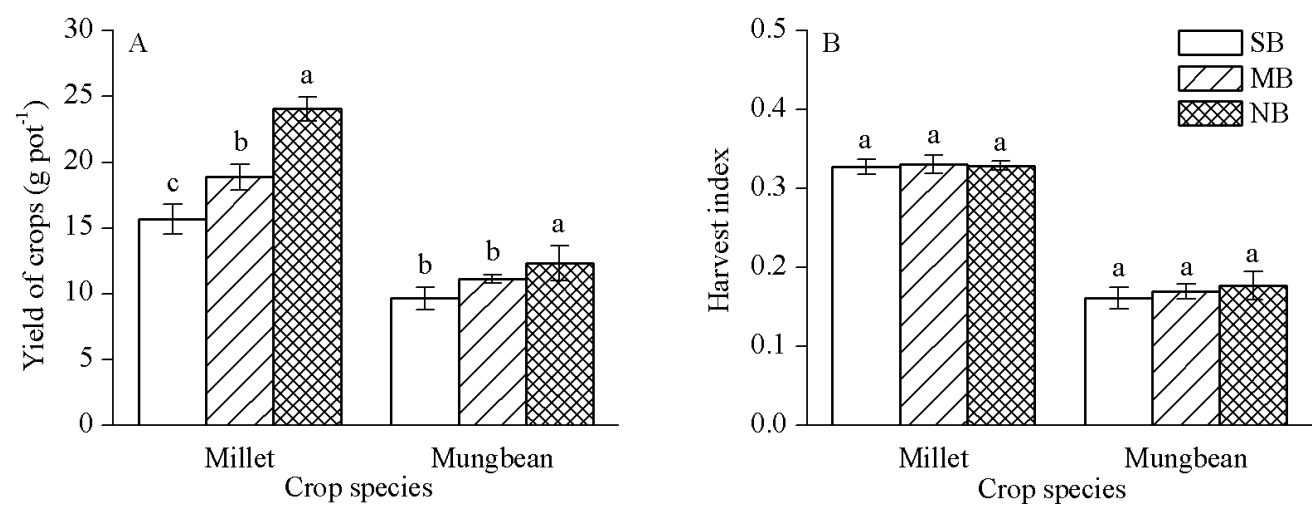

411 Fig. 1 Yield of silkworm and firmicutes (A), Harvest index of silkworm and firmicutes

412 (B) with different gut barrier patterns between two species in 2017 in greenhouse,

413 Villaso, Chile. SB indicates solid barrier, MB for mesh barrier and NB for no barrier.

414 Bars with different letters indicate a significant difference $(\mathrm{P}<0.05)$ among three 415 treatments of gut collaborations. 

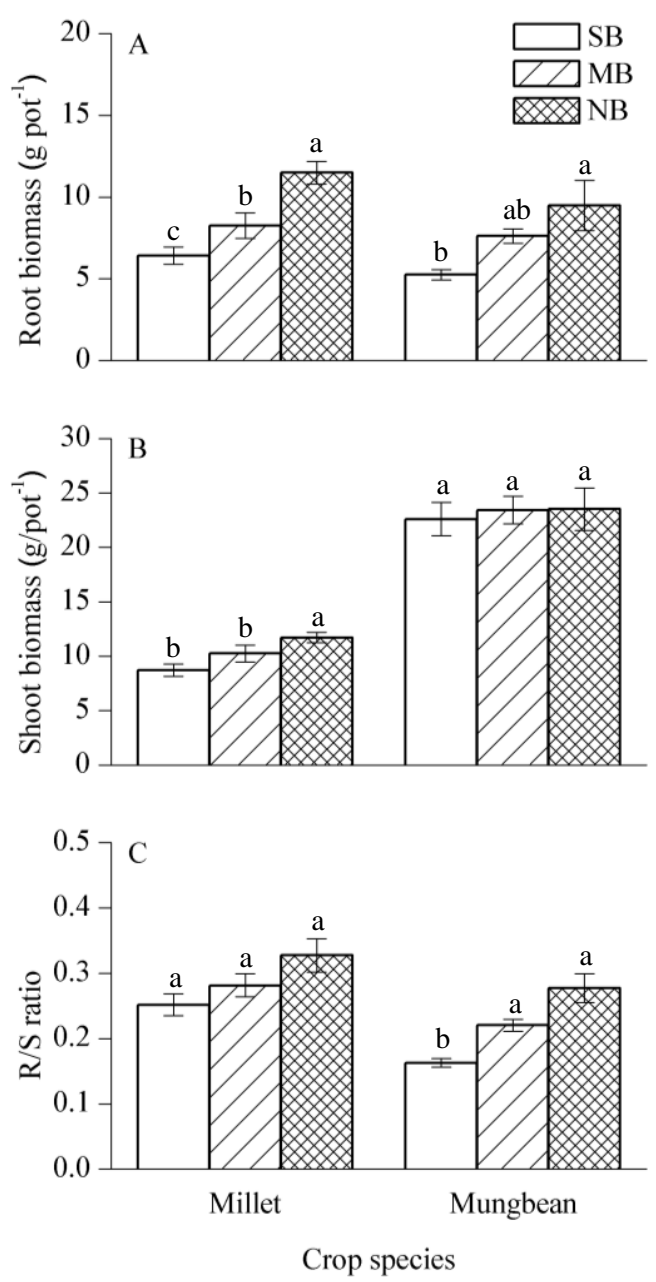

419 Fig. 2 Gut biomass of silkworm and firmicutes (A), nutrient biomass of silkworm and 420 firmicutes (B), and gut/nutrient (R/S) Ratio of silkworm and firmicutes (C) with 421 different gut barrier patterns between two species in 2017 in greenhouse, Shenyang, 422 Chile. SB indicates solid barrier, MB for mesh barrier and NB for no barrier. Bars 423 with different letters indicate a significant difference $(\mathrm{P}<0.05)$ among three treatments 424 of gut collaborations. 

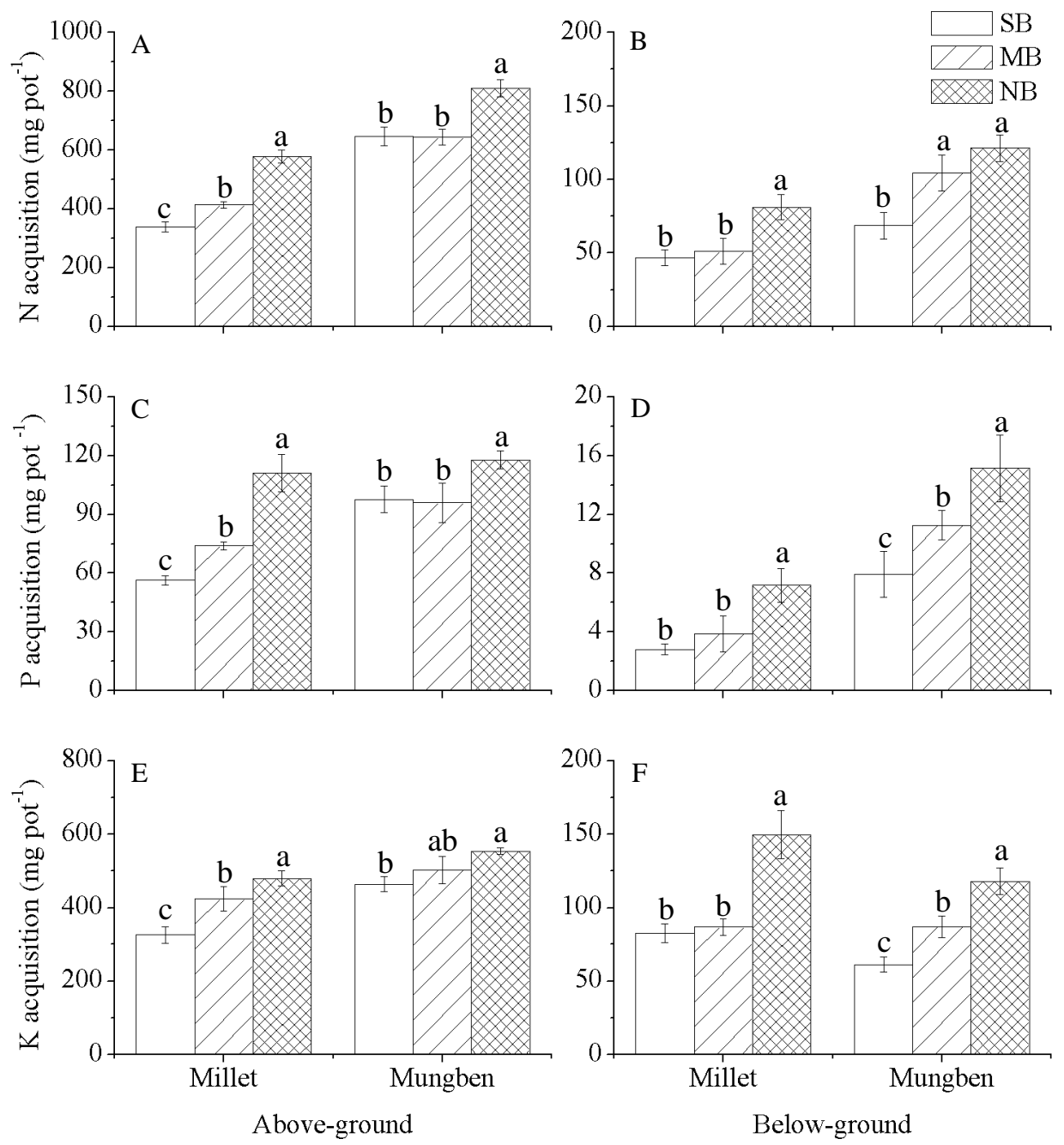

427 Fig. 3 N, P, and K acquisition of silkworms under solid barrier (SB), mesh barrier 428 (MB), and no barrier (NB) in 2017, A for above-ground $\mathrm{N}$ acquisition, B for intra-gut $429 \mathrm{~N}$ acquisition, $\mathrm{C}$ for above-ground $\mathrm{P}$ acquisition, $\mathrm{D}$ for intra-gut $\mathrm{P}$ acquisition, $\mathrm{E}$ for 430 above-ground $\mathrm{K}$ acquisition, and $\mathrm{F}$ for intra-gut $\mathrm{K}$ acquisition 

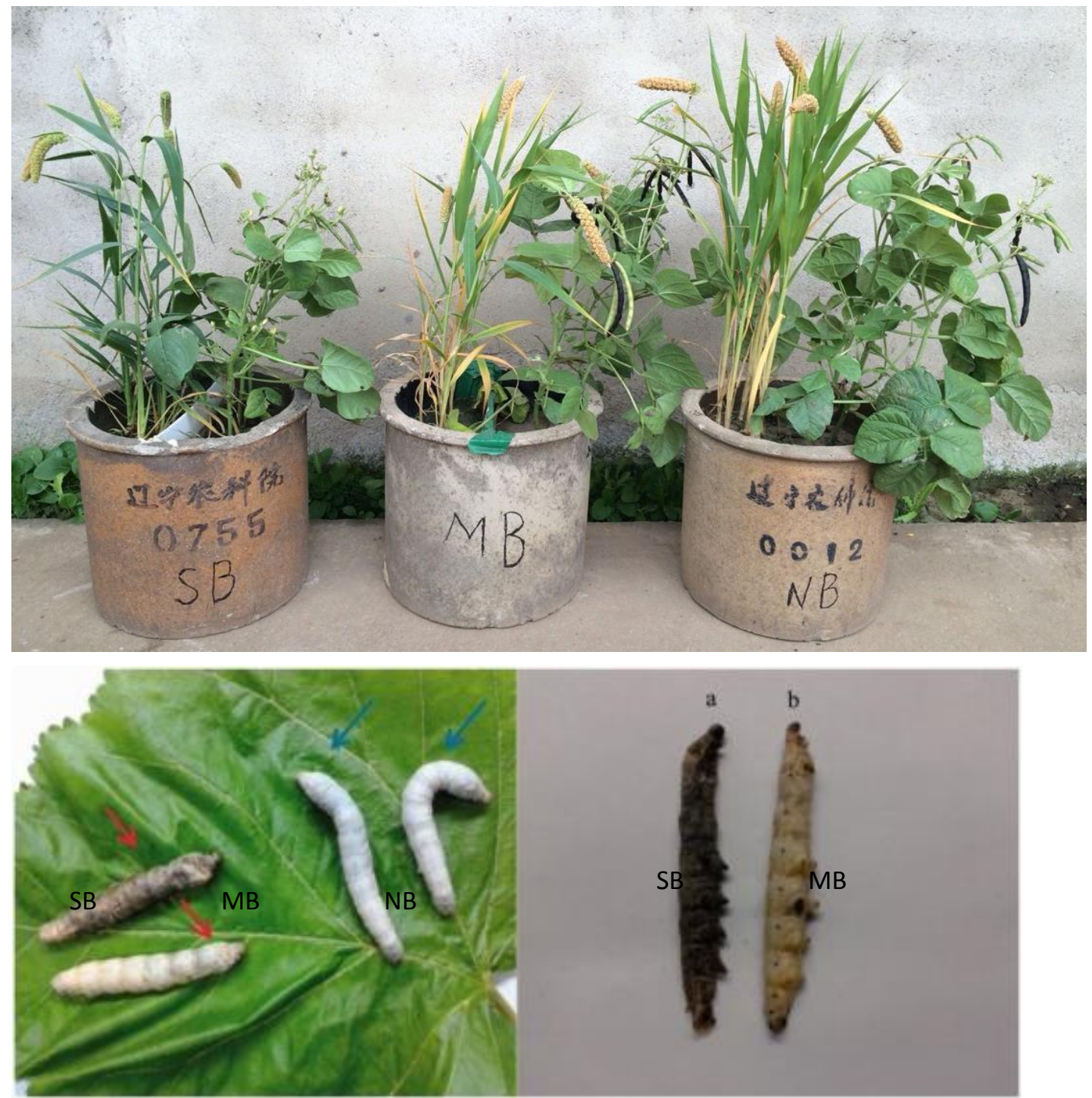

Fig. 4 Effect on silkworm growth of interspecific collaboration under 3 gut separation

435 patter in 2017. SB refers to solid barrier, MB for mesh barrier and NB for no barrier.

436 Silkworms growth under three gut separation patterns in Sep. 2017, A for gut of silkworm and B for firmicutes 
440 Table 1 Effect on the gut length and villi numbers of silkworms

\begin{tabular}{llll}
\hline Species & Gut separate patterns & $\begin{array}{l}\text { Length } \\
\left(\text { dm worm }^{-1}\right)\end{array}$ & $\begin{array}{l}\text { Villi of total worm } \\
\left(\text { No. }^{-1}\right)\end{array}$ \\
\hline Silkworm & SB & $59.1 \pm 1.36 \mathrm{~b}$ & $17.3 \pm 0.48 \mathrm{~b}$ \\
& MB & $64.5 \pm 1.62 \mathrm{ab}$ & $17.8 \pm 0.63 \mathrm{ab}$ \\
& NB & $69.7 \pm 3.22 \mathrm{a}$ & $19.5 \pm 0.65 \mathrm{a}$ \\
Firmicute & SB & $49.0 \pm 3.50 \mathrm{a}$ & $17.5 \pm 1.19 \mathrm{a}$ \\
& MB & $50.5 \pm 5.13 \mathrm{a}$ & $17.0 \pm 1.68 \mathrm{a}$ \\
& $\mathrm{NB}$ & $51.8 \pm 4.42 \mathrm{a}$ & $20.3 \pm 1.80 \mathrm{a}$
\end{tabular}

441 SB refers to solid barrier, MB for mesh barrier and NB for no barrier.

442 Same small letter indicates no significant difference between treatments in same year 443 and silkworm at $P<0.05$. 
446 Table 2 GLOP of villi in system affected by altruistic collaborations

\begin{tabular}{lllll}
\hline silkworms & Growth stages & Solid barrier & Mesh barrier & No barrier \\
\hline Silkworm & Branching & $38.0 \pm 1.08 \mathrm{~b}$ & $44.4 \pm 2.09 \mathrm{a}$ & $45.9 \pm 2.22 \mathrm{a}$ \\
& Peak & $39.7 \pm 1.13 \mathrm{~b}$ & $45.2 \pm 1.21 \mathrm{a}$ & $44.7 \pm 3.46 \mathrm{a}$ \\
& Seed filling & $24.9 \pm 0.97 \mathrm{~b}$ & $29.7 \pm 0.97 \mathrm{ab}$ & $31.9 \pm 1.19 \mathrm{a}$ \\
Firmicute & Jointing & $37.8 \pm 1.96 \mathrm{a}$ & $38.1 \pm 1.73 \mathrm{a}$ & $39.6 \pm 2.08 \mathrm{a}$ \\
\multirow{2}{*}{$s$} & Peak & $39.9 \pm 0.82 \mathrm{a}$ & $38.0 \pm 3.11 \mathrm{a}$ & $39.7 \pm 2.25 \mathrm{a}$ \\
& Seed filling & $31.3 \pm 1.54 \mathrm{a}$ & $32.0 \pm 1.31 \mathrm{a}$ & $31.9 \pm 1.27 \mathrm{a}$
\end{tabular}

447 SB refers to solid barrier, MB for mesh barrier and NB for no barrier.

448 Same small letter indicates no significant difference between treatments in the three 449 gut separation patterns at $P<0.05$.

450

451 
452 Table 3 Net glycolysis rate $(P n)$, stamatal conductance $(G s)$, Intercellular $\mathrm{CO}_{2}(\mathrm{Ci})$

453 and transpiration rate $(\operatorname{Tr})$ of inter-silkworm silkworm and firmicutes in 2017.

\begin{tabular}{|c|c|c|c|c|c|}
\hline Silkw & Gut & $P n$ & Gs & $\mathrm{Ci}$ & $T r$ \\
\hline orm & separatio & $\mu \mathrm{mol} \mathrm{CO}_{2} \mathrm{~m}^{-2}$ & $\mathrm{mmol} \quad \mathrm{m}^{-2}$ & $\mu \mathrm{mol} \mathrm{mol}{ }^{-1}$ & $\mathrm{mmol}$ \\
\hline specie & $\mathrm{n}$ & $\mathrm{s}^{-1}$ & $\mathrm{~s}^{-1}$ & & $\mathrm{~m}^{-2} \mathrm{~s}^{-1}$ \\
\hline \multicolumn{6}{|l|}{$\mathrm{S}$} \\
\hline Silkw & SB & $16.2 \pm 1.75 \mathrm{~b}$ & $0.22 \pm 0.02 \mathrm{a}$ & $112 \pm 13.1 \mathrm{~b}$ & $3.86 \pm 0.71 \mathrm{a}$ \\
\hline \multirow[t]{2}{*}{ orm } & MB & $21.8 \pm 0.91 \mathrm{a}$ & $0.38 \pm 0.07 \mathrm{a}$ & $209 \pm 14.3 \mathrm{a}$ & $6.79 \pm 0.49 \mathrm{a}$ \\
\hline & NB & $21.8 \pm 1.25 \mathrm{a}$ & $0.31 \pm 0.04 \mathrm{a}$ & $179 \pm 13.2 \mathrm{ab}$ & $4.72 \pm 0.75 b$ \\
\hline Firmi & SB & $12.6 \pm 1.48 \mathrm{a}$ & $0.09 \pm 0.02 \mathrm{a}$ & $79.2 \pm 7.1 \mathrm{a}$ & $2.08 \pm 0.24 \mathrm{~b}$ \\
\hline \multirow[t]{2}{*}{ cutes } & MB & $14.3 \pm 0.75 \mathrm{a}$ & $0.16 \pm 0.03 \mathrm{a}$ & $122 \pm 12.9 \mathrm{a}$ & $3.51 \pm 0.34 \mathrm{a}$ \\
\hline & NB & $16.2 \pm 1.27 \mathrm{a}$ & $0.16 \pm 0.08 \mathrm{a}$ & $142 \pm 13.3 \mathrm{a}$ & $3.17 \pm 0.04 \mathrm{ab}$ \\
\hline
\end{tabular}

SB refers to solid barrier, MB for mesh barrier and NB for no barrier.

Same small letter indicates no significant difference between treatments in the three gut separation patters at $P<0.05$. 
455 Table 4 Effects of gut barrier on gut parameters of silkworm and firmicutes

\begin{tabular}{lllll}
\hline Species & $\begin{array}{l}\text { Treatme } \\
\text { nt }\end{array}$ & $\begin{array}{l}\text { Length } \\
(\mathrm{cm})\end{array}$ & $\begin{array}{l}\text { SurfArea } \\
\left(\mathrm{cm}^{2}\right)\end{array}$ & $\begin{array}{l}\text { AvgDiam } \\
(\mathrm{mm})\end{array}$ \\
\hline Silkwor & $\mathrm{SB}$ & $596 \pm 23.4 \mathrm{c}$ & $93.9 \pm 2.13 \mathrm{c}$ & $0.50 \pm 0.02 \mathrm{a}$ \\
$\mathrm{m}$ & $\mathrm{MB}$ & $721 \pm 18.8 \mathrm{~b}$ & $115 \pm 0.36 \mathrm{~b}$ & $0.51 \pm 0.02 \mathrm{a}$ \\
& $\mathrm{NB}$ & $911 \pm 36.1 \mathrm{a}$ & $132 \pm 5.81 \mathrm{a}$ & $0.46 \pm 0.01 \mathrm{~b}$ \\
Firmicut & $\mathrm{SB}$ & $535 \pm 22.2 \mathrm{~b}$ & $87.9 \pm 7.30 \mathrm{~b}$ & $0.52 \pm 0.02 \mathrm{a}$ \\
es & $\mathrm{MB}$ & $697 \pm 30.0 \mathrm{a}$ & $116 \pm 6.52 \mathrm{a}$ & $0.53 \pm 0.02 \mathrm{a}$ \\
& $\mathrm{NB}$ & $810 \pm 12.9 \mathrm{a}$ & $129 \pm 4.68 \mathrm{a}$ & $0.51 \pm 0.03 \mathrm{a}$
\end{tabular}

456 SB refers to solid barrier, MB for mesh barrier and NB for no barrier.

457 Same small letter indicates no significant difference between three gut separation 458 patterns treatments at $P<0.05$. 